\title{
Ambiências, expografias e seus objetos: a imigração alemã no sul do Brasil a partir das narrativas museológicas
}

\author{
Ambiences, expographies and its objects: the German immigration in \\ southern Brazil from museological narratives
}

Ambientes, expografias y sus objetos: la inmigración alemana en el sur de Brasil partir de la narrativa museológica

\section{Resumo}

Objetiva-se discutir os museus de imigração alemã no Rio Grande do Sul como lugares de memória. Como recorte espacial, trabalha-se com uma amostragem de instituições situadas nas diferentes zonas de colonização do estado. Atentamos especialmente para a expografia dos museus que, dessa forma, veiculam e difundem representações sobre a identidade étnica ligada à imigração alemã no sul do Brasil.

Palavras-chave: Imigração alemã. Memória e patrimônio. Museus.

* Doutora em História pela Pontifícia Universidade Católica do Rio Grande do Sul, Brasil. Professora do Programa de Pós-Graduação da Universidade de Passo Fundo, Brasil. E-mail: meyrer_nh@hotmail.com

** Doutora em História pela Pontifícia Universidade Católica do Rio Grande do Sul, Brasil. Professora do Programa de Pós-Graduação da Universidade de Passo Fundo, Brasil. E-mail: rosaneneumann@ upf.br

**** Doutor em História pela Universidade do Vale do Rio dos Sinos, Brasil. Professor das Faculdades Integradas de Taquara, Brasil. E-mail: danielgevehr@hotmail.com

Recebido em 01/04/2016 - Aprovado em 01/09/2016 http://dx.doi.org/10.5335/hdtv.16n.2.6927 


\section{Considerações iniciais}

Entende-se o museu como um espaço de preservação - e difusão - de narrativas visuais, que se expressam em sua expografia e nas diferentes ambiências. Essas, por sua vez, revelam por intermédio de seus arquivos - constituídos de objetos, documentos, imagens e um vasto repertório de fontes - representações sobre a história do processo de imigração e colonização alemã no Rio Grande do Sul. Nesse contexto, os museus de imigração merecem destaque em nossa investigação, uma vez que se apresentam como um importante espaço de diálogo permanente entre as diferentes formas de escrita sobre o passado - ou as narrativas produzidas sobre esse passado em expografia museológica - nas comunidades nas quais a etnicidade, nesse caso germânica, e a valorização daquilo que se considera como sendo do lugar, aparecem de forma mais expressiva (PAIVA, 2014).

Seguindo esse propósito, estabeleceram-se como recorte espacial os museus de história da imigração alemã localizados em regiões coloniais do Vale do Sinos e do Noroeste Colonial, que se configuram como parte da produção visual sobre a imigração alemã no Rio Grande do Sul. Nesse caso, interessa compreender em que medida as narrativas visuais (BURKE, 2004) presentes nas exposições museológicas ligadas à imigração alemã - tendo clara a ideia de que cada narrativa procura difundir uma dada história a partir de seu contexto de produção - presentes nesses espaços museológicos (POSSAMAI, 2010), imprimem no meio social diferentes representações sobre a história da imigração alemã no sul do Brasil.
Os recortes e as seleções, presentes nos seus acervos museológicos, materializam e externalizam o trabalho envolvido na afirmação de uma memória, perpassada pela subjetividade dos sujeitos envolvidos, determinando a memória a ser mostrada e reforçada, e a memória a ser invisibilizada, e no limite, esquecida. Nesse processo de manipulação da memória, prevalecem os interesses de diferentes grupos sociais, e essas representações e narrativas visuais muitas vezes são lidas como verdades absolutas pelos frequentadores desses espaços.

\section{Os museus e seus objetos: as operações no campo da memória e da identidade}

$\mathrm{Na}$ perspectiva de interpretar os $\mathrm{mu}$ seus (POULOT, 2013) como elementos de legitimação de determinadas representações sobre a história dos alemães no sul do Brasil, procura-se realizar uma leitura crítica sobre a criação desses espaços, com o propósito de compreender os museus como portadores e reprodutores de mecanismos de memória (POLLAK, 1989), que operam a partir da criação/seleção de ambiências (MENESES, 2013), bem como a difusão de imagens e representações (JODELET, 2001) que expressam uma história sobre a imigração alemã.

Salienta-se que o presente estudo está ancorado nas discussões contemporâneas sobre os elementos simbólicos (BOURDIEU, 2001), presentes nesses lugares de memória (NORA, 1993; SUTTON, 2012) da imigração alemã. Na complexa engrenagem que opera a produção desse patrimônio, é preciso considerar as possíveis relações entre as categorias de patrimônio cultural, de identidade étnica e do papel da educação patrimonial no fazer pedagógico. 
Logo, é perceptível nesses espaços de reprodução da memória, uma forte preocupação com a expressão e afirmação de representações associadas à identidade étnica. Essa perspectiva é fundamental em nossa análise, uma vez que os traços identitários se materializam nas representações presentes nos museus (BORGES, 2011) por meio da produção de suas exposições permanentes e temporárias, que revelam objetos e coleções que evidenciam a identidade do grupo representado. Entende-se identidade, conforme Candau, como "uma construção social, de certa maneira sempre acontecendo no quadro de uma relação dialógica com o Outro", em que memória - elemento indispensável da construção da identidade de uma comunidade - é "uma construção continuamente atualizada do passado, mais do que uma construção fiel do mesmo" (CANDAU, 2012, p. 9).

Nessa perspectiva, compreendemos os museus da imigração alemã como (re) produtores de memória (LE GOFF, 2003) da imigração na região em que se encontram, uma vez que esses espaços desempenham uma tarefa de perpetuação e ressignificação dessa memória para os imigrantes. Essa memória, por sua vez, pode revelar escolhas e enquadramentos da memória (POLLAK, 1989) dos grupos que as produzem, definindo inclusive aquilo que deve - ou pode - ser mostrado na expografia dos museus.

Cabe ainda trazer à tona a discussão acerca das produções simbólicas (BOURDIEU, 2001) que se fazem presentes nos museus, uma vez que as exposições nem sempre "falam" simplesmente por intermédio da materialidade de seus objetos, mas também de sua disposição na expografia e pelo contexto ideológico e até mesmo iconográfico em que estão inseridos. Os museus podem, assim, ser compreendidos como manifestações simbólicas, que falam de forma direta ou indireta, carregados de subjetividade - podendo ser lidos como um texto, uma narrativa sobre o passado - sobre o lugar e sobre os grupos sociais responsáveis pela sua produção, em um processo que envolve um campo de lutas simbólicas (CHARTIER, 2002), no qual a imposição de determinadas representações sobre $o$ passado (BOURDIEU, 2001) sofrem - necessariamente - a seleção daquilo que deve ser preservado e representado nos espaços sociais. Buscando aprofundar a leitura crítica sobre esses espaços, retomamos Chartier (2002), que aponta para as inúmeras possibilidades de leitura de um símbolo, fazendo-nos refletir que esste símbolo não é "lido" de uma única maneira. Segundo ele, existem diferentes formas de interpretação de um símbolo, já que sua leitura está diretamente vinculada ao contexto no qual o observador está inserido.

Os museus são também espaços de comunicação, de narrativa fundamental na (re) elaboração da memória, na (re)construção e fixação das identidades. Para Ricoeur (2007), a relação entre a memória individual e coletiva se dá pela narrativa construída sobre as experiências vividas. A memória funda-se na linguagem, que se torna a portadora da memória, fortalecida em narrativas coletivas. Nesse aspecto, a memória narrada nos museus históricos constitui-se uma forma específica de narrar o mundo, por meio de representações do real com base na memória, sendo que o seu significado depende do tipo de relações que o museu estabelece com a comunidade e sua memória. 
A narrativa da memória realizada nos museus históricos com base em objetos é feita nas exposições, essência da linguagem museológica, cuja vantagem sobre o discurso historiográfico, fundamentalmente verbal, é a diversidade e pluralidade que os objetos materiais visuais possibilitam. Já Menezes não concebe o museu como narrativa, mas atribui às exposições seu caráter fundamental, que define "como convenção visual, organização de objetos para produção de sentido" (1994, p. 22).

O museu, portanto, constrói e comunica sentidos a partir da exposição de seu acervo. A equipe de profissionais que atua no museu organiza as exposições, fundamentando-as em seu acervo e em determinado espaço, seguindo a lógica e os conceitos por eles elaborados, construindo representações e/ou interpretações sobre um determinado contexto histórico. Nesse sentido, consideramos que as exposições são a principal forma de mediar a relação entre o público e o patrimônio material ali exposto, o que nos leva a pensar sobre os processos de patrimonialização dos objetos, processo que está ligado à identidade do grupo (comunidade, nação, classe...) que a instituição (museu) pretende representar. Devemos considerar que as representações sociais (JODELET, 2001) expressam parte dos sentimentos e das ideologias dos grupos que as forjam e definem ainda os objetos eleitos para representá-los. Por sua vez, essas definições partilhadas - e que nesse caso se materializam nos espaços museológicos das comunidades teuto-sul-rio-grandenses - constroem uma visão pretensamente consensual da realidade.

Vinculando as discussões sobre museu com o campo de produção e apropriação das comunidades locais, é importante lembrar que os museus de imigração exercem papel social como lugares de memória, na acepção de Nora, para quem a "memória pendura-se em lugares como a história em acontecimentos" (1993, p. 25). Nesse jogo de relações, trata-se de espaços socialmente construídos, constituídos por mecanismos daquilo que Halbwachs (2004) chamou de processo de perpetuação da memória, visto que os lugares de memória atuam na construção da memória coletiva, pois os lugares que percorremos, lembram-nos dos fatos do passado, contribuindo para a construção da memória, na medida em que evocam o passado.

Já Pollak (1989) analisa os lugares de memória - como os museus e suas coleções - como espaços de preservação de memória, que passam a ser reconhecidos por suas comunidades. A criação dos museus de imigração, investigados neste estudo, ocorreu em um período em que essas comunidades passavam por profundas transformações, como a chegada de migrantes de outras regiões do Rio Grande do Sul - o que fez com que ocorresse uma divesificação significativa na composição étnica - e os fenômenos da industrailização e da urbanização, impulsionados, principalmente, a partir da década de 1970.

Dessa forma, esses museus passaram a ser vistos pelos grupos responsáveis pela sua criação como lugares de salvaguarda de uma memória imigrante, que não queria se "perder no tempo". Sua expografia é uma tentativa de patrimonialização do passado, que revela ainda uma visão sobre patrimônio associada à noção de "patrimônio de cal e pedra". Enfim, devemos considerar que $O$ imaginário (BACZKO, 1985) tem como um de seus pontos de referência - e de lembrança esses lugares de memória. 
A lembrança aponta para a necessidade de uma constante atualização (LE GOFF, 2003). Os museus da imigração contribuem exatamente para isso, na medida em que suas exposições permitem a manutenção e a atualização de uma memória projetada sobre o próprio grupo que a produziu e a preserva - dessa forma, serve de suporte para a operacionalização dos processos que constituem a (re)produção da memória. Nesse contexto, cabe questionar como se operam esses processos de constituição da memória - que envolvem também lembranças e esquecimentos (RICOEUR, 2012) sobre a imigração alemã nessas comunidades elencadas, problematizando os mecanismos que envolvem o direito à memória (LEAL, 2012) dos diferentes grupos, que, muitas vezes, são silenciados ou excluídos pelos grupos detentores do poder, em especial, nas esferas locais/regionais, onde ocorre a eleição/seleção das memórias materializadas nos arquivos e nas expografias museológicas.

Nessa perspectiva, a criação e a organização de um museu de história ligado a um grupo étnico devem ser compreendidas como um fenômeno social, no qual se dá a (re)definição sobre o passado, que considera a preservação dos traços identitários como forma de representação do passado a partir de um regime de historicidade (HARTOG, 2014) que elege o tempo presente como perspectiva de criação dessas narrativas visuais. O museu desempenha uma função de "aparelho ideológico da memória" (CANDAU, 2012, p. 158), o que se explica, uma vez que o patrimônio da comunidade pode ser compreendido como um verdadeiro transmissor da memória do grupo, agregando valores, ideologias e formas de pensar. Além disso, o museu passa a representar parte do passado dessa comunidade, que se encontra "patrimonializado" nesse espaço.

Para pensar a relação existente entre patrimônio e sua produção, Candau afirma que

[...] a história do patrimônio é a história da construção do sentido de identidade e, mais particularmente, aquela dos imaginários de autenticidade que inspiram as políticas patrimoniais $(2012$, p. 159).

Seguindo essa lógica, a lembrança dos primeiros imigrantes serve de suporte da memória, para mostrar aos visitantes o desenvolvimento de suas comunidades, ao mesmo tempo que reafirma e legitima a representação almejada sobre e para o grupo étnico germânico.

Essas narrativas, por sua vez, revelam um processo de produção dos valores de etnicidade (POUTIGNAT; STREITFF-FENART, 1998), que se tornam evidentes nessas expografias, carregadas de valores e sentimentos étnicos (SEYFERTH, 2011), que, dessa forma, evidenciam a necessidade de expressar, por meio de objetos e diferentes ambiências, sua relação direta com o grupo étnico do qual são descendentes. O estudo sobre os museus de imigração revelou um esforço da parte dos grupos que os produzem em reafirmar sua íntima relação com a germanidade, o que nos leva a pensar sobre a identidade étnica compartilhada pela própria comunidade, que lembra e perpetua o passado imigrante, por intermédio dos museus.

Partindo da ideia de que a produção das identidades inicia-se em um processo que envolve a marcação das diferenças e que elas ocorrem em sistemas simbólicos de representação (WOODWARD, 2014), entende-se os museus também como um fenômeno 
do patrimônio cultural que busca construir uma identidade sobre o grupo responsável pela sua criação e manutenção. Daí ser possível considerar aquilo que Choay afirma, quando procura inserir o museu enquanto uma expressão desse patrimônio, na medida em que ele pode ser interpretado como

[...] um bem destinado ao usufruto de uma comunidade que se ampliou a dimensões planetárias, constituído pela acumulação contínua de uma diversidade de objetos que se congregam por seu passado comum (2001, p. 11).

Com isso, o patrimônio cultural pode ser visto como fruto da identidade de uma comunidade, que ao mesmo tempo nos revela a presença de diferentes interesses e opera diretamente no campo da manipulação da memória coletiva.

O museu - compreendido como essa expressão do patrimônio cultural da contemporaneidade - engloba ainda saberes, lugares e modos de fazer, que buscam "comunicar algo" sobre a identidade e que, consequentemente, são transmitidos através das gerações. Dessa relação, é possível afirmar que os hábitos e as tradições de uma comunidade nos dizem e revelam muito sobre parte da sua cultura, que no atual contexto da globalização passa a ser mais uma questão que preocupa historiadores e aqueles que ensinam história no contexto escolar.

\section{0 patrimônio cultural da imigração alemã: as narrativas visuais no Rio Grande do Sul}

Conforme Gonçalves, no complexo jogo de forças, "por meio do qual se dá o fluxo de trocas entre doadores e diretores de museus"
(2009, p. 178-179) é que se define/seleciona aquilo que será colocado na expografia do museu. A partir daí, é possível acompanhar o processo de "invenção do patrimônio", que, para o autor, consiste na seleção e organização do museu, que, por seu turno, "vem acompanhada de valores, como autonomia e liberdade, assumidos por sujeitos individuais ou coletivos" (2009, p. 179) da comunidade, envolvida no processo.

Partindo desses pressupostos, o estudo pretende compreender como os museus que têm como tema a imigração alemã no sul do Brasil narram a história desse grupo de imigrantes e seus descendentes. Quais as escolhas, dentro de um universo de lembranças e objetos, que mereceram atenção para serem rememoradas e quais os esquecimentos? Quais os elementos demarcadores do grupo em relação aos outros e que constituem a sua identidade?

O sul do Brasil é um polo de referência da imigração alemã, onde se concentra o maior número de indivíduos dessa ascendência bem como de comunidades que ainda mantém fortes características étnicas. Desde o início de sua instalação em território brasileiro, os grupos de imigrantes preocuparam-se com a preservação da memória, tanto familiar quanto coletiva. Essa preocupação esteve presente na fundação das diversas associações culturais e recreativas bem como de igrejas e escolas de caráter étnico, criadas desde os primórdios de imigração no Estado, em um processo de "institucionalização de identidades" (WEBER, 2008, p. 236). Sendo os imigrantes, por definição, indivíduos desconectados espacialmente de seu passado, vivendo uma situação de duplicidade de 
identidade, ocupando um "lugar bastardo entre o ser e não ser social" (BOURDIEU, 1998, p. 11), a construção de lembranças tornou-se fundamental na (re)elaboração de sua identidade no novo território, na medida em que a memória, na sua acepção mais básica, é a presença do passado. Porém, não o passado em si, mas a sua representação seletiva, sendo que essa seleção - o que esquecer e o que lembrar - é definida pelo grupo familiar, social, étnico, nacional. Essa preocupação com a preservação e reatualização da memória pode ser identificada pela quantidade de museus, arquivos e monumentos construídos, sobretudo, após a Segunda Guerra Mundial, passada a chamada fase da nacionalização, período no qual as comunidades de imigrantes e seus descendentes foram proibidos de manifestar sua cultura.

Apresentados os pressupostos teóricos, é propósito deste estudo descrever e comparar a narrativa das exposições de longa duração ou permanentes de três museus das chamadas zonas de colonização alemã, os dois primeiros localizado na zona pioneira, considerada "berço" da colonização alemã no Rio Grande do Sul, o Museu Histórico Visconde de São Leopoldo e o Museu Municipal Adolfo Evaldo Lindenmeyer, o terceiro, na nova zona colonial do Planalto sul-rio-grandense, o Museu Antropológico Diretor Pestana.

\section{Museu Visconde de São Leopoldo}

O Museu Histórico Visconde de São Leopoldo (MHVSL) foi criado em 1959, como Museu da Imigração Alemã. Sua sede fica no município de São Leopoldo, porém é fruto da colaboração de dez municípios originários da colonização alemã. Sua fundação ocorreu no final do período da nacionalização, quando houve um reavivamento das práticas culturais relativas à imigração alemã, buscaram-se antigos símbolos e construíram-se novos que "remetessem à memória social relacionada aos imigrantes e descendentes de alemães" (WEBER, 2012, p. 30).

No processo de fundação e consolidação do MHVSL, várias campanhas foram realizadas, com palestras em locais públicos e pela imprensa, a fim de conscientizar a comunidade da necessidade da (re)construção da identidade do grupo. Campanhas também foram feitas para coleta de material para o museu em um processo de patrimonialização dos objetos que passavam a integrar o acervo. Todo esse movimento tinha como objetivo "a constituição de uma memória coletiva e pública que contribuíram para a reconstrução da identidade de um grupo" (WEBER, 2012, p. 31).

Atualmente, o MHVSL, nas palavras de presidente da entidade José Carlos Eggers, é "um museu, um arquivo histórico e uma biblioteca" (EGGERS, 2012, p. 163), pretendendo tornar-se um centro cultural com cursos de línguas, música, palestras, entre outros. Em discurso proferido em 2009, Eggers (2012) também salientou que o MHVSL não se atém mais exclusivamente à identidade étnica alemã, mas sim às diferentes etnias que formaram os municípios da região, em uma atualização dos objetivos e dos discursos sobre o museu em conformidade com as novas demandas sociais, cuja pauta norteia-se pelo discurso do multiculturalismo e pela diversidade. Embora haja um esforço no sentido de integrar todos os grupos na 
exposição do museu, a fala de Eggers, bem como a própria exposição, revela um discurso hierárquico sobre os papéis atribuídos aos diferentes grupos.

Ao observar a exposição de longa duração proposta no MHVSL, percebe-se que predomina o discurso étnico em uma visão tradicional, na qual os objetos patrimonializados são aqueles referentes às camadas mais altas da sociedade, que, na medida em que se constituem os principais fornecedores dos objetos do acervo, elegem o que deve ser considerado como representativo da memória do grupo. Capovilla, ao classificar as exposições nos museus alusivos à imigração alemã no Rio Grande do Sul, entre os quais se insere o MHVSL, afirma que:

[...] os objetos que compõe as exposições de longa duração nesses museus (onde o forte não é a pesquisa) são escolhidos em geral pelo seu visual e pela sua procedência. Assim, o mais bonito, o mais rico está exposto. Neste caso, a mostra vai incidir sobre a riqueza e o sucesso de alguns poucos imigrantes detentores de capital econômico e estas representarão o todo (2014, p. 50).

Esses objetos, na sua maioria, estão expostos em vitrines, agrupados em temáticas, como: infância (brinquedos), acessórios femininos (objetos de adorno e material de costura), acessórios masculinos (cachimbos, canecas de chope, bengalas, jogos), imprensa (máquinas impressoras, jornais em alemão, livros e material de escritório), música (instrumentos musicais, pianos, violinos, saxofone, gramofone), fotografias (álbuns e material fotográfico), escola (livros didáticos, lousa e demais materiais escolares) e armas (espingardas, espadas, entre outros equipamentos bélicos).
O prédio do Museu tem dois andares, com a exposição de longa duração concentrada no andar térreo. No andar superior, encontram-se o arquivo de documentos e fotografias, a biblioteca, a cinemateca e a reserva técnica. Esse andar é de visitação restrita a pesquisadores. O MHVSL sedia também o Instituto Histórico de São Leopoldo, criado em 1975, cujo principal enfoque é desenvolver a pesquisa sobre a imigração e colonização alemã.

Ao entrar no MHVSL, três objetos de grande porte chamam a atenção: um automóvel ano 1928, doado por um colaborador do museu, um púlpito de madeira, oriundo da Igreja Matriz de 1912, e uma grande "estátua do colono", que está em frente à porta de entrada, representando o imigrante a saudar os visitantes. A estátua fazia parte do Monumento ao Imigrante, situado na praça que integra o centro histórico da cidade, no qual está o prédio do museu. Devido a atos de vandalismo, em 2004, decidiu-se que a estátua iria para o MHVSL. Não se pretende aqui estudar a estátua como monumento em si, mas sim sua representação no conjunto da exposição, portanto, enquanto um elemento simbólico na narrativa museográfica. Entende-se que a estátua possui elementos simbólicos de distinção ao lado de outros que representam o colono desbravador: o "colono" representado está bem vestido, usando traje completo (colete, paletó, cajado e sobretudo), sua expressão é sóbria e apresenta um ar de satisfação, esboçando um meio sorriso, que remete à representação do imigrante vencedor. Por outro lado, as botas são elementos simbólicos tradicionalmente associados ao elemento desbravador do colonizador/conquistador. 
O carro entra no rol daqueles objetos selecionados por seu valor visual e de procedência, citados por Capovilla (2014). O automóvel no início do século, quando a imigração já tinha cem anos, era um objeto de luxo, símbolo da modernidade, mas já acessível àquela parcela do grupo que havia enriquecido e usufruía de um estilo de vida que poderíamos chamar de burguês. $\mathrm{O}$ outro objeto de grande porte é um púlpito de madeira em cujo pedestal encontra-se uma bíblia em alemão. A presença da Igreja, tanto católica quanto luterana, foi um elemento fundamental na organização das antigas colônias, exercendo um forte poder de controle sobre a comunidade. Sua representação destacada no museu reforça a sua forte presença na construção da memória do grupo.

Na mesma sala, a um canto, sob a escada, quase invisíveis, há artefatos indígenas: uma urna funerária, um pilão de erva-mate, objetos de artesanato indígena. Essas peças estão reunidas em um espaço de pouca visibilidade, e como não é lugar de passagem, podem passar despercebidas para o visitante menos atento.

O roteiro proposto leva a uma ampla sala ao lado, onde se encontra o núcleo central da exposição. Na entrada, o visitante depara-se com um imenso mural contendo diversas fotografias de imigrantes e descendentes em diferentes atividades, especialmente àquelas ligadas à valorização da identidade étnica do grupo, como as sociedades de canto, de tiro e de ginástica. Essas sociedades eram expressões da identidade étnica em um período em que, passadas as dificuldades iniciais de instalação, um grupo mais próspero poderia dedicar-se a horas de lazer e cultivo aos valores culturais germânicos. Uma única fotografia, no painel, retrata o trabalho braçal (lavadeiras no rio). Tem-se a impressão que foi dada uma "licença" para colocar, ali, ao menos uma imagem daqueles imigrantes que não fizeram parte da epopeia de sucesso descrita na historiografia tradicional.

Segue-se a exposição das vitrines. No primeiro ambiente ${ }^{1}$ estão os objetos de valor mais elevado: pratarias, louças de porcelana, instrumentos musicais (piano, violino, gramofone, entre outros dispositivos). Junto a esse acervo - no mesmo ambiente - está uma vitrine que remete aos afrodescendentes: uma série de utensílios utilizados para realização de tortura. Embora um texto em um cartaz na vitrine aponte para uma tentativa de desconstrução do discurso, informando que os alemães não conviveram com a escravidão, ou que foram mais brandos. Chama a atenção o fato de que os únicos elementos dos afrodescendentes expostos thes atribuem um papel social específico naquela sociedade, ou seja, a narrativa corrobora identificar o negro como única e exclusivamente ligado ao elemento servil.

O ambiente seguinte é composto por várias vitrines, cujos objetos estão organizados por temas, conforme já assinalado. Nas paredes, há retratos de pessoas distintas na comunidade e quadros de alvos ornamentados das sociedades de tiro. Dois conjuntos se destacam entre os demais: as armas, que estão nas vitrines ao centro e, ao fundo, um conjunto relativo ao material da imprensa alemã. ${ }^{2}$

As armas, em parte, eram utilizadas nas sociedades de tiro, que estão representadas na exposição dos alvos decorados nas paredes desse mesmo ambiente. Elas representam 
também a caça e mesmo a defesa dos primeiros imigrantes. Esses objetos parecem adequar-se aquela representação do colono na estátua de bronze na entrada, na medida em que representa tanto o imigrante vencedor, que já possui um determinado status social, que lhe permite realizar atividades de lazer nas sociedades que surgiam, como as de tiro, ao mesmo tempo, as armas apontam para sua representação de desbravador. Da mesma forma, a importância dada à produção do material impresso representa o nível cultural do grupo, um elemento fundamental de distinção em um país de grande maioria analfabeta à época. Essa distinção, entretanto, dá-se no interior do próprio grupo étnico, uma vez que um contingente de imigrantes e descendentes permaneceu sem acesso a essa cultura letrada.

Essa breve descrição da exposição possibilita identificá-la como uma narrativa histórica conservadora, que reforça os estereótipos construídos pela historiografia tradicional da imigração alemã que, de forma ufanista, narra o processo de imigração e colonização como uma epopeia, cujos heróis, os imigrantes, prosperaram e trouxeram o progresso à região. Nesse processo tiveram de se defender dos índios e animais selvagens - com as armas. No movimento de adaptação, acabaram adotando alguns elementos da cultura portuguesa, entre eles a adoção de escravos. À medida que prosperavam, encarregavam-se de trazer da Alemanha uma série de utensílios louças, instrumentos musicais, roupas, móveis. Objetos que, expostos no MHVSL, são representativos do imigrante alemão. Cabe perguntar por aqueles - a maioria - que não saíram das "picadas". Esses objetos os repre- sentam? Não são eles também integrantes desse mesmo grupo étnico?

Embora na exposição do MHVSL perceba-se uma tímida tentativa de trazer outros discursos à tona, como inserir os afrodescendentes e os índios dentro do museu, essa manifestação ainda é feita dentro dos limites do discurso oficial, no qual a integração desses outros é feita de acordo com os papéis que lhe foram historicamente atribuídos. Assim, acreditamos que a narrativa da exposição do MHVL reforça o discurso da supremacia do imigrante europeu na medida em que coloca o índio literalmente embaixo da escada e os negros unicamente como escravos.

\section{Museu Municipal Adolfo Evaldo Lindenmeyer}

O segundo espaço museal investigado é o Museu Municipal Adolfo Evaldo Lindenmeyer (MMAEL) - que presta homenagem ao ex-vereador e descendente de alemães -, situado na área central do município de Sapiranga, no prédio da antiga estação férrea, conhecida como Estação Sapyranga, desativada em 1964. O museu foi criado pela prefeitura em 1996 e tem como tema principal de seu acervo a imigração e a colonização alemã.

Sapiranga está localizada no Vale do Sinos e atualmente é conhecida nacionalmente como a Cidade das Rosas e do Voo Livre. A chegada dos primeiros colonizadores alemães foi em 1845 , com a compra dos primeiros lotes de terras, que foram comercializados pela Sociedade Schmidt e Kraemer. A história da localidade foi, ainda, marcada pelo episódio dos Mucker (1868-1874), em que, liderados pelo casal Maurer, os prati- 
cantes de uma espécie de culto doméstico e com práticas curativas por meio de plantas e ervas medicinais acabaram sendo exterminados pelas forças oficiais do governo.

A emancipação de Sapiranga do município de São Leopoldo ocorreu em 1955, motivada pelo desenvolvimento econômico produzido pela indústria calçadista e pela crescente urbanização. Desde então, o município é conhecido nacionalmente como grande produtor e exportador de calçados, atividade econômica que prevalece atualmente. A marca do passado abalizado pela imigração alemã está presente ainda hoje, especialmente por meio da denominação de logradouros públicos, monumentos e também pela caracterização de seus moradores, que é, em grande parte, de origem germânica.

A exposição permanente do museu apresenta um acervo distribuído em diferentes ambientes organizados por temas, referentes à história da cidade. As temáticas são: emancipação política, a venda colonial, a moradia do imigrante e o desenvolvimento econômico do município, nessa ordem. Além disso, o museu conta com uma pequena exposição de obras que retratam o episódio dos Mucker - único movimento messiânico ocorrido no Brasil em ambiente protestante e que foi liderado por uma mulher, Jacobina Mentz Maurer. ${ }^{3}$

Assim, logo na entrada, o tema da emancipação, remete à municipalidade, criadora da instituição. Objetos, como a mesa do prefeito e diversos instrumentos do trabalho cotidiano do primeiro prefeito, apresentam o discurso político de constituição do município, certificando ou oficializando-o como uma unidade política administrativa do Es- tado brasileiro, para, em seguida, explicar o processo de sua origem.

No espaço expográfico seguinte, há a representação de uma venda colonial, que existiu na localidade desde o século XIX e funcionava em uma edificação em estilo enxaimel. Os diferentes objetos expostos visam narrar parte da história da comunidade, em especial a economia de trocas de produtos, (re)conhecida em toda região colonial alemã do Rio Grande do Sul, como elemento propulsor do desenvolvimento econômico.

Essas vendas podem ser consideradas patrimônio cultural da zona de colonização alemã do Rio Grande do Sul, pois se constituem espaços reconhecidos pela comunidade como parte de uma lembrança ligada aos antepassados imigrantes. Ao lado da Igreja e das muitas sociedades de lazer fundadas pelos imigrantes e seus descendentes, eram espaços de prestígio, um dos principais locais, muitas vezes o único, onde se desenvolviam as relações econômicas, sociais e políticas das pequenas comunidades. Sua importância manteve-se na maioria das comunidades até meados do século $X X$, quando a intensificação do desenvolvimento urbano traz consigo novos espaços de sociabilidade. Cabe ainda enfatizar que a venda permanece no imaginário da região colonizada pelos imigrantes alemães como motor inicial da prosperidade econômica dos imigrantes.

Já a moradia do imigrante é representada pela cozinha e pelo quarto do casal, que mostram parte do mobiliário e dos objetos de uso cotidiano, dispostos cronologicamente, criando uma narrativa linear, composta por um conjunto de artefatos de diferentes épocas e contextos da história de Sapiranga. 
O quarto e a cozinha são representativos do modo de vida e valores das comunidades teutas no sul do Brasil, no que diz respeito ao seu universo doméstico. A cama do casal acompanhada do berço, os símbolos da religiosidade e retratos da família nas paredes evidenciam um modelo de família cultivado pelos colonos e seus descendentes. Os objetos dispostos valorizam a ideia de família e praticamente anulam a de casal. Essa valorização da família pode ser explicada pelas extensas famílias formadas pelas primeiras gerações de imigrantes, decorrente, em parte, da necessidade de braços para o trabalho.

A mesma ideia é expressa na representação da cozinha, em cujo centro há uma mesa com o banco onde a família se sentava para fazer as refeições coletivamente. Os utensílios domésticos, de diferentes épocas, dispostos no ambiente, também representam outro elemento da identidade étnica: a gastronomia germânica, atualmente muito explorada pelo turismo na região de imigração, em um processo de reelaboração e apropriação da identidade alemã. Essa culinária colonial está ligada a todo um ritual do preparo artesanal de diferentes produtos, reconhecido como característico do grupo, podendo ser considerado como parte de seu patrimônio cultural, representando saberes e fazeres. Assim, objetos como formas para confecção de bolachas, doces em compotas, moedor de café e outros vários utensílios são colocados em relevo na exposição. Os panos de parede com dizeres em alemão - e de grande apelo religioso - completam o significado étnico do ambiente.

O Museu apresenta também uma exposição cuja temática é o desenvolvimento da indústria calçadista, principal atividade econômica do município na atualidade. Embora não haja consenso, alguns autores afirmam que foi o capital acumulado pelos comerciantes da zona colonial que possibilitaram o posterior desenvolvimento da indústria (ROCHE, 1969). Essa parece ser a tônica da narrativa apresentada pelo museu, na medida em que se inicia com a representação das primeiras casas comerciais. Da mesma forma, estabelece a ligação da prosperidade econômica, oriunda do calçado, ao elemento germânico.

A ideia de progresso é representada ainda na área externa do museu, onde se encontra uma réplica da estrada de ferro, inaugurada em 1903, que ligava Sapiranga a Porto Alegre. A presença da estrada de ferro é compreendida pela comunidade como representação do desenvolvimento econômico da localidade no final do século XIX, logo após o desfecho do conflito dos Mucker, que encerrou em 1868, com a vitória das forças imperiais sobre o grupo liderado por Jacobina nas imediações do morro Ferrabraz. Os trilhos do trem simbolizam, nesse contexto, o progresso alcançado pelos alemães e seus descendentes.

\section{Museu Antropológico Diretor Pestana}

O processo de imigração e colonização no Brasil foi acompanhado por um movimento interno paralelo: a remigração, ocorrendo de uma colônia à outra, ou dentro da própria colônia - além do retorno dos (i) migrantes. No final do século XIX, esse movimento de pessoas tornou-se mais intenso ainda e a distância entre o lugar de saída e de destino cada vez maior. No Rio Grande do Sul, houve a migração das colônias velhas 
para as colônias novas, entre as colônias novas e, principalmente a partir da década de 1920, das colônias novas para o oeste catarinense, e assim sucessivamente. Todo projeto de colonização ao se lançar, carregava consigo uma leva de migrantes, atraídos pela possibilidade de adquirirem (mais) terras para si e seus filhos, por preços reduzidos, na perspectiva de permanecer/tornarem-se proprietários, multiplicando seu capital (ROCHE, 1969; NEUMANN, 2009).

Nesse contexto, em 1890 foi fundada a colônia pública de ljuí, no então município de Cruz Alta, no Planalto sul-rio-grandense, dentro do projeto republicano positivista de colônia mista, tanto étnica quanto religiosa. Na sua formação, recebeu significativo número de imigrantes, dentre eles, alemães, austríacos, letos, suecos, poloneses, italianos, holandeses, árabes, todavia, predominaram os colonos provenientes da remigração interna.

A colônia de Ijuí foi contemplada com um ramal ferroviário em 1891, fato que facilitou a circulação de pessoas e mercadorias. Seu rápido crescimento populacional e desenvolvimento socioeconômico culminou na sua emancipação já em 1912. Na lógica da colonização, tal qual São Leopoldo no século XIX, Ijuí representava o núcleo colonial central no Planalto na virada para o século XX. Partindo desse pressuposto, é pertinente perceber como os museus estabelecidos nesses dois espaços "pioneiros" elaboraram suas narrativas.

Ijuí construiu uma identidade pautada na ideia de etnias diversificadas, embora, como um todo, prevaleça a identidade de colônia alemã. Dar visibilidade a essa diversidade étnica foi cogitado apenas na década de 1980, quando foi realizada uma feira, a Expo-ljuí (1981). Visando incrementar a feira, e com apoio de um grupo de professores universitários da Fundação de Integração, Desenvolvimento e Educação do Noroeste do Estado (Fidene)/Universidade Regional do Noroeste do Estado do Rio Grande do Sul (Unijuí), acrescentou-se à exposição uma festa, a Festa Nacional das Culturas Diversificadas, em 1987. A partir de então, reforça-se esse discurso, sintetizado, por exemplo, no slogan da exposição de 2014: "A origem nos define. A união nos fortalece". ${ }^{4}$

O Museu Antropológico Diretor Pestana (MADP), foi fundado em 25 de maio de 1961, junto ao Centro de Estudos e Pesquisas Sociais da Faculdade de Filosofia, Ciências e Letras de Ijuí, atual Unijuí, e é mantido pela Fidene. ${ }^{5}$ No rol de seus objetivos, consta "resgatar e preservar a memória regional, promover a cultura, a educação e o lazer" além de ser uma "síntese da evolução da região pela mão do nosso homem...". ${ }^{6}$ Tal qual o MHVSL, pretende-se guardião da história regional, formando o seu acervo a partir da coleta de peças e doações. Esse discurso está evidente também no site da instituição nos dizeres: "Memória de Ijuí e do noroeste do estado do Rio Grande do Sul", "Conheça os aspectos da caminhada do homem que viveu e vive em Ijuí e região". A mesma pretensão está expressa na sua visão: “constituir-se em Centro Museológico e Documental pela preservação da memória, promoção da cultura, da educação e do lazer na região Noroeste do RS". Atribui-se como missão "constituir programas museológicos e documentais, com características antropológicas, que contribuam para a melhoria do processo educacional 
e cultural na Região". ${ }^{7}$ No painel de apresentação da exposição, consta que o museu iniciou suas atividades com a doação do acervo do Dr. Martin Fischer, e o seu objetivo maior consiste "em contar e retratar a vida".

Relativo à sua estrutura e acervo, conta com um amplo prédio com área de $1.618 \mathrm{~m}^{2}$, climatizado, que abriga a parte de arquivo e museu, além de auditório. O seu acervo está distribuído na exposição de longa duração, no andar superior, e em exposições temporárias, que ocupam uma sala na parte inferior do prédio. Tendo em vista a diversidade do acervo sob sua guarda, organiza-se nas Divisões de Museologia, Documentação e Imagem e Som.

A Divisão de Museologia tem por objetivo

[...] acondicionar, conservar, documentar e expor os objetos doados ao MADP. Além de tais competências, possui o compromisso de preservar a memória dos acervos museológicos e o dever de ressignificá-los, para que assumam sua função museal. ${ }^{8}$

É responsável pela pesquisa, elaboração e montagem das exposições de longa duração e as exposições temporárias. Conta com aproximadamente 30 mil peças no acervo, subdivididos em quatro seções: Antropologia, Arqueologia, Numismática e Filatelia e Artes Visuais, sendo que as duas últimas constam na reserva técnica, em fase de estudo e inventário. ${ }^{9}$

A narrativa construída pela exposição de longa duração do MADP segue inicialmente uma linha cronológica linear, orientada pela distribuição espacial das peças, e posteriormente, uma organização temática. $\mathrm{O}$ discurso da diversidade étnica, que é difícil de ser trabalhado em termos de linguagem museal, é substituído pela linguagem presente na historiografia clássica da imigração e colonização, ou seja, o trabalho e a contribuição dos imigrantes para o desenvolvimento da colônia, independente da origem étnica, embora na exposição predomine em larga escala o acervo doado/a contribuição da etnia alemã.

O acervo exposto, na maior parte, está acondicionado em vitrines, com peças identificadas e painéis explicativos. A primeira sessão dedica-se a artefatos arqueológicos em pedra, cerâmica e ossos, que remetem à presença do índio pré-missioneiro da região. Parcela do acervo é oriunda de pesquisas arqueológicas realizadas entre os anos 1967 e 1973, em 134 sítios, e o restante de coleta avulsa, totalizando aproximadamente 24.217 peças arqueológicas. A maior parte desse acervo permanece na reserva técnica.

Seguindo essa narrativa e dividindo ainda o mesmo espaço na exposição, apresenta-se o índio missioneiro, acompanhado de um histórico sobre os Sete Povos das Missões. Mais adiante, o índio kaingang, representado por seu artesanato, e o guarani. Chega-se então na seção de antropologia, dividida em Índio, Missões e Povoamento. Essa divisão denota que anterior à chegada dos imigrantes europeus e colonos, não havia um efetivo povoamento.

O negro está presente em um painel na exposição, remetendo a um sujeito histórico específico, que teria vivido em Ijuí, com informações gerais sobre a presença dos negros escravos na região. Já o caboclo está representado vinculado ao extrativismo da erva-mate, encerrando a presença do outro, anterior ao processo de colonização. 
O restante da exposição trata da formação histórica da colônia Ijuí e o seu desenvolvimento. A primeira sequência de painéis ocupa-se com a fundação da colônia, destacando o diretor Augusto Pestana como personagem central desse processo. Há ainda um mapa histórico da divisão da colônia e imagens fotográficas de época. Os imigrantes são representados por um casal de imigrantes alemães e o baú de viagem, acompanhado de um painel, remetendo à presença de imigrantes de diferentes nacionalidades.

A partir de então, a expografia adota uma linguagem temática, na qual predomina efetivamente a exposição do acervo de peças. O discurso apresenta em primeiro plano a agricultura, incluindo utensílios vinculados ao cotidiano do meio rural, como plantio, colheita, processamento de produtos e domésticos. Em paralelo, há peças e painéis relacionados aos meios de comunicação, especialmente jornais e rádios. Depois, apresentam-se as fábricas artesanais e a sua maquinaria, a indústria e o comércio, juntamente aos meios de transporte e a produção de energia elétrica.

Outro conjunto de objetos diversos versa sobre a prestação de serviços, incluindo hotel, farmácia, banco, barbearia, alfaiate, fotógrafo, dentista, hospital. Em seguida, inicia a exposição relacionada à cultura, ao lazer, à educação e à religiosidade, como a expressão musical - corais e conjuntos musicais -, espaços de sociabilidade e práticas esportivas; brinquedos, instituições de ensino, incluindo o surgimento da universidade, espaços e artefatos religiosos vinculados ao catolicismo e protestantismo.
A última parte da exposição traz os costumes da colônia e artefatos do cotidiano das famílias. Representam festas, como casamentos, acessórios e vestimentas femininas, além de um espaço, com um andar superior em madeira, que reproduz a casa de uma família alemã, demarcando todos os seus ambientes, incluindo sala, cozinha, quarto e banho, com seu respectivo mobiliário.

\section{Considerações finais}

Constata-se que as três narrativas museográficas trazem como fio condutor a imigração alemã e os seus sujeitos históricos, imbricados na formação e desenvolvimento dos núcleos coloniais. Como lugares de memória, esses museus apresentam perfis e propostas distintas: o MHVSL, com um discurso mais difuso e claramente identificado como um espaço de memória da imigração alemã. Já o MMAEL, de formação mais recente, propõe-se a narrar a história do município, centralizada na figura do imigrante alemão como seu elemento fundador. O MADP tem por trás uma instituição universitária, com profissionais formados em diferentes áreas específicas, o que se reflete na estrutura e organização do acervo, todavia, a composição de seu acervo acentua a presença dos imigrantes e descendentes de alemães, embora o discurso se esforce para mostrar a multiplicidade étnica.

Os museus são lugares de memória onde se (re)produzem narrativas e discursos sobre os artefatos, em geral, mediados por agentes que possuem algum destaque na sociedade representada, seja econômico-social, cultural ou político. Desse entendimento, po- 
demos inferir que as três instituições analisadas refletem, também, os interesses dos grupos que os idealizaram, criaram e os mantém. Assim, o MHVSL foi idealizado e construído por um grupo constituído essencialmente pela comunidade germânica, o que faz com que esse traço seja o principal condutor de sua na'rrativa. MADP, por conta da constituição acadêmica do grupo fundador, acaba por diluir a identidade étnica na narrativa, na medida em que enquadra o discurso no modelo científico consensual, explícito em seu próprio nome, que remete a um campo científico, a antropologia. Já o MMAEL traz a marca da oficialidade, é ela quem conduz o discurso caracterizado, entretanto, pela preponderância do elemento imigrante.

Podemos inferir essa questão a partir da linguagem visual dos três museus. Se no MVSL o visitante é recebido pela figura do imigrante na porta da entrada, que o conduz à exposição, no MADP, é o elemento indígena, legitimado por estudos científicos (arqueologia), quem recepciona o visitante; já no MMAEL, há um rompimento simbólico e o discurso constrói-se a partir do processo político, nesse caso, a emancipação do município. Em todos eles, mesmo partindo de perspectivas distintas, há como elemento central o discurso da identidade étnica alemã e do papel do imigrante como agente fundador e promotor da prosperidade das referidas localidades.

Portanto, as narrativas visuais dos museus, entendidos como lugares de memória da imigração alemã no Rio Grande do Sul, perfazem o patrimônio histórico-cultural dessas comunidades e ocupam um lugar de excelência, como guardiões da memória e na construção/reatualização da identidade étnica dos grupos envolvidos.

\section{Abstract}

The objective is to discuss the German immigration museums in Rio Grande do Sul as places of memory. As spatial area, working with a sample of institutions located in different state colonization zones. We alert especially for expography of museums, therefore, convey and disseminate representations of ethnic identity linked to the German immigration in Southern Brazil.

Keywords: German immigration. Memory and heritage. Museums.

\section{Resumen}

El objetivo es discutir los museos de inmigración alemana en Rio Grande do Sul como lugares de memoria. Como área espacial, se trabaja con una muestra de instituciones ubicadas en diferentes zonas de colonización del Estado. Alertamos sobre todo para la impresión de los museos de este modo transmitir y difundir representaciones de la identidad étnica vinculado a la inmigración alemana en el sur de Brasil.

Palabras clave: Inmigración alemana. Memoria y patrimonio. Museos.

\section{Notas}

1 A sala da exposição é dividida pelos balcões das vitrines. Assim, tem-se dois ambientes de exposição.

2 Os imigrantes alemães tiveram uma forte atuação na imprensa sul-rio-grandense, produzindo 
diversos jornais, almanaques e livros didáticos. Uma ativa intelectualidade germânica encarregou-se de difundir os valores culturais germânicos, conhecidos por Deutschtum. Importante frisar que essa imprensa atingia, predominantemente, aqueles elementos do grupo que já haviam conquistado alguma distinção social e, inclusive espacial, distanciando-se daqueles que ficaram nas "picadas".

3 A exposição sobre os Mucker conta com apenas uma vitrine onde estão expostas livros produzidos sobre o tema. No mês de agosto, quando se rememora o final do conflito, o museu apresenta uma exposição temporária com diversos banners que contam os principais momentos que marcaram a história dos Mucker e, principalmente, sobre a atuação de Jacobina. O tema dos Mucker e a problemática dos lugares de memória produzidos sobre eles em Sapiranga é aprofundado por Gevehr (2007).

4 Disponível em: <http://expoijuifenadi.com.br/ home-banner/>. Acesso em: 19 out. 2014.

5 A Ordem dos Frades Franciscanos (capuchinhos) do Rio Grande do Sul, instalados em Ijuí, vinculados ao ensino, fundaram em 1956 a Faculdade de Filosofia, Ciências e Letras de Ijuí (Fafi). Posteriormente, em 1969, o patrimônio da Fafi passou à Fidene, hoje mantenedora da Unijuí, do MADP, do Centro de Educação Básica Francisco de Assis e da Rádio Educativa Unijuí. Em 1993, após a formalização do caráter regional e multicampi, transformou-se na Universidade Regional do Noroeste do Estado do Rio Grande do Sul, Unijuí. Disponível em: <http://www.unijui.edu.br/ institucional/sobre-a-unijui>. Acesso em: 7 nov. 2014

6 Disponível em: <http://www.unijui.edu.br/ museu>. Acesso em: 22 out. 2014.

7 Disponível em: <http://www.unijui.edu.br/ museu>. Acesso em: 22 out. 2014.

8 Disponível em: <http://www.unijui.edu.br/ museu>. Acesso em: 22 out. 2014.

9 Disponível em: <http://www.unijui.edu.br/ museu>. Acesso em: 22 out. 2014.

\section{Referências}

BACZKO, Bronislaw. Einaudi. Lisboa: Antropos, 1985.

BORGES, Maria Eliza Linhares. Inovações, coleções, museus. Belo Horizonte: Autêntica, 2011.
BOURDIEU, Pierre. O poder simbólico. 4. ed. Rio de Janeiro: Bertrand, 2001.

Um analista do inconsciente. In: A IMIGRAÇÃO ou os paradoxos da alteridade. São Paulo: Edusp, 1998. p. 9-12.

BURKE, Peter. Testemunha ocular: história e imagem. Bauru: EDUSC, 2004.

CANDAU, Jöel. Memória e identidade. São Paulo: Contexto, 2012.

CAPOVILLA, Eloisa Helena da Luz Ramos. $\mathrm{O}$ que guardam e o que mostram os museus de imigração? In: BERTRUY, Ramona I. Pérez. Estudios sobre el patrimonio documental, digital y cultural de America Latina. México, 2014. Disponível em: <http://pt.slideshare.net/smgemexico/estudios-sobre-el-patrimonio-documental-digital-y-cultural-de-amrica-latina>. Acesso em: 25 out. 2014.

CHARTIER, Roger. À beira da falésia: a história entre certezas e inquietudes. Porto Alegre: Ufrgs, 2002.

CHOAY, Françoise. A alegoria do patrimônio. São Paulo: Editora Unesp, 2001.

EGGERS, José Carlos; LINCK, Márcio (Org.). Museu Histórico Visconde de São Leopoldo: 50 anos de história. Novo Hamburgo: Um Cultural, 2012.

GEVEHR, Daniel Luciano. Pelos caminhos de Jacobina: memórias e sentimentos (res)significados. 287 p. Tese (Doutorado em História) - Programa de Pós-Graduação em História, Universidade do Vale do Rio dos Sinos, São Leopoldo, 2007.

GONÇALVES, José Reginaldo Santos. Os museus e a cidade. In: ABREU, R.; CHAGAS, M. (Org.). Memória e patrimônio: ensaios contemporâneos. 2. ed. Rio de Janeiro: Lamparina, 2009. p. 171-186.

HALBWACHS, Maurice. A memória coletiva. São Paulo: Centauro, 2004. 
HARTOG, François. Regimes de historicidade. Presentismo e experiências do tempo. Belo Horizonte: Autêntica, 2014.

JODELET, Denise. Representações sociais: um domínio em expansão. In: (Org.). As representações sociais. Rio de Janeiro: EDUERJ, 2001.

LEAL, Rogério Gesta (Org.). Verdade, memória e justiça: um debate necessário. Santa Cruz do Sul: EDUNISC, 2012. Disponível em: <http:/ / www.portalmemoriasreveladas.arquivonacional.gov.br/media/verdadememoriaejustica. pdf $>$. Acesso em: 18 set. 2015.

LE GOFF, Jacques. História e memória. 5. ed. Campinas: Unicamp, 2003.

MENESES, Ulpiano T. Bezerra de. Do teatro da memória ao laboratório da História: a exposição museológica e o conhecimento histórico. Anais do Museu Paulista, [S.1.], v. 2, n. 1, p. 9-42, jan. 1994. Disponível em: <http:// www.revistas.usp.br/anaismp/article/ view/5289/6819>. Acesso em: 25 out. 2014.

MENESES, Ulpiano T. Bezerra de. A exposição museológica e o conhecimento histórico. In: FIGUEIREDO, B. G.; VIDAL, D. G. Museus: dos gabinetes de curiosidades à museologia moderna. 2. ed. Belo Horizonte: Fino Traço, 2013. p. 15-88.

NEUMANN, Rosane Marcia. Uma Alemanha em miniatura: o projeto de imigração e colonização étnico particular da Colonizadora Meyer no noroeste do Rio Grande do Sul (1897-1932). 2009. Tese (Doutorado em História) - Programa de Pós-Graduação em História, Pontifícia Universidade Católica, Porto Alegre, 2009.

NORA, Pierre. Entre memória e história. A problemática dos lugares. Projeto História - Revista do Programa de Estudos Pós-graduados em História e do Departamento de História PUC-SP, São Paulo, n. 10, p. 7-28, dez. 1993.

PAIVA, Odair da Cruz. Museus e memória da imigração: embates entre o passado e o presente. In: LEAL, Elisabete; PAIVA, Odair da Cruz. Patrimônio e história. Londrina: Unifil, 2014. p. 157-170.
POLLAK, Michael. Memória, esquecimento, silêncio. Estudos Históricos, Rio de Janeiro, v. 2, n. 3, p. 3-15, 1989.

POSSAMAI, Zita Rosane. As artimanhas do percurso museal: narrativas sobre objetos e peças de museu. Revista Museion, Canoas, v. 4, n. 7, p. 64-72, jan./jun. 2010.

POULOT, Dominique. Museu e Museologia. Belo Horizonte: Autêntica, 2013.

POUTIGNAT, Philippe; STREITFF-FENART, Jocelyne. Teorias da etnicidade. São Paulo: Unesp, 1998.

RICOEUR, Paul. A memória, a história, o esquecimento. Campinas: Unicamp, 2012.

ROCHE, Jean. A colonização alemã e o Rio Grande do Sul. Porto Alegre: Globo, 1969. 2 v.

SEYFERTH, Giralda. A dimensão cultural da imigração. Revista Brasileira de Ciências Sociais, São Paulo, v. 26, n. 77, p. 47-62, 2011.

SUTTON, John. Memory. The Stanford Encyclopedia of Philosophy. Inverno, 2012. Disponível em: <http://plato.stanford.edu/archives/win2012/entries/memory/>. Acesso em: 25 jul. 2015.

WEBER, Roswithia. Características do contexto de valorização de elementos coloniais na formação do turismo. In: SIDEKUM, A.; GRÜTZMANN, I.; ARENDT, I. C. (Orgs.). Campos Múltiplos: identidade, cultura e história. São Leopoldo: Oikos, 2008.

O papel do museu no reavivamento étnico. In: EGGERS, José Carlos; LINCK, Márcio. (Org.). Museu Histórico Visconde de São Leopoldo - 50 anos de história. Novo Hamburgo: [s.n.], 2012. v. 1. p. 31-33.

WOODWARD, Kathryn. Identidade e diferença: uma introdução teórica e conceitual. In: SILVA, T. T. da (Org.). Identidade e diferença: a perspectiva dos estudos culturais. 14. ed. Petrópolis: Vozes, 2014. p. 7-72. 